\title{
Comparative Evaluation of Laboratory based Mass Cultivation System of Microalgae for Biodiesel Production
}

\author{
R. Kiruthika ${ }^{1 *}$ and S. Kamaraj ${ }^{2}$ \\ ${ }^{1}$ Department of Agricultural Engineering, RVS School of Engineering and Technology, \\ Dindigul-05, Tamil Nadu, India \\ ${ }^{2}$ Department of Bio-energy, Agricultural Engineering College and Research Institute, \\ Tamil Nadu Agricultural University, Coimbatore - 641 003, Tamil Nadu, India \\ *Corresponding author
}

\begin{tabular}{|c|c|}
\hline \multicolumn{2}{|r|}{ A B S T R A C T } \\
\hline & \multirow{7}{*}{$\begin{array}{l}\text { Global biofuel production has tripled from } 4.8 \text { billion gallons to about } 16 \text { billion, concerns } \\
\text { about energy security and soaring oil prices have driven policymakers and scientists to } \\
\text { develop alternative energy sources. Currently, algae are considered as potential biomass } \\
\text { feedstock sources for the production of advanced biofuels. Algae can be cultivated in } \\
\text { unproductive lands and poor quality waters. Worldwide, the current research focus is } \\
\text { mainly on identifying the algal strains with higher lipid content (i.e. above } 40 \text { per cent } \\
\text { triglycerides in the biomass) and biomass productivity for mass cultivation. By growing } \\
\text { lipid rich strains in large scale, the oil yield can be enhanced which can be converted into } \\
\text { biodiesel and blended with petrodiesel to replace significant quantities of fossil fuels. } \\
\text { Three microalgal samples Botryococcus sp., Chlorella sp. and Tetradesmus wisconsinensis } \\
\text { were selected and screened for fast growth and high oil content. Also they are grown } \\
\text { outdoors in either paddle-wheel mixed ponds or circular ponds with a rotating mixing arm. } \\
\text { More recently, a helical tubular, cylindrical and airlift photobioreactor system, has been } \\
\text { developed which allows these algae to be grown reliably outdoors at high cell densities in } \\
\text { semi-continuous culture. The main problem facing the commercialisation of new } \\
\text { microalgae is the need for closed culture systems and the fact that these are very capital } \\
\text { intensive. Although this problem has been avoided in some instances by growing the algae } \\
\text { heterotrophically, not all algae or algal products can be produced this way. }\end{array}$} \\
\hline Keywords & \\
\hline & \\
\hline & \\
\hline Article Info & \\
\hline & \\
\hline & \\
\hline
\end{tabular}

\section{Introduction}

Chisti (2008) reported that algae can be cultivated in farms absorbing carbon dioxide from the air. They contain oils that can be used as raw material for biodiesel production. They have the advantage that they do not conflict with food production. In addition, they have the potential to cover the global demand for transportation fuels. Algae were cultivated as biofuel feedstock mainly due to their high productivity of oil and less land requirement. The production of oil from microalgae range from $5.87 \mathrm{~L} \mathrm{~m}^{-2}$ to $13.69 \mathrm{~L}$ $\mathrm{m}^{-2}$, which is $10-23$ times higher than that of the highest oil producing terrestrial oil crop palm (Demirbas, 2011). The required land space is 10-340 times smaller than that of their terrestrial counterparts. Physicochemical characterization of algal oils have been 
studied recently with a reported $\mathrm{pH}$ in the range of $6-7$, density in the range of 0.85 $0.89 \mathrm{~g} \mathrm{~cm}^{-3}$, and viscosity in the range of 3.8 $4.4 \mathrm{~mm}^{2} \mathrm{~s}^{-1}$ (Kumar et al., 2011).

The economic biodiesel production from microalgae requires enormous bulk of algal biomass. Practically, convenient commercial scale production of algal biomass can be achieved by two feasible methods (i) Conventional open ponds systems and (ii) Closed photobioreactors (Patil et al., 2005 and Carvalho et al., 2006).

Open culture systems are almost always located outdoors and rely on natural light for illumination (Terry and Raymond, 1985). The control of contaminants in open pond systems is the most important problem. The open ponds have a variety of shapes and sizes depending upon the location of cultivation. An assessment of open ponds for algal cultivation by the United States Department of Energy (DOE) suggested that such ponds should have standard dimensions of $10 \mathrm{~m}$ width, $100 \mathrm{~m}$ length and $30 \mathrm{~cm}$ depth built in concrete blocks, on a $10 \mathrm{~cm}$ thick sole for optimized biomass growth. A paddle wheel (raceway systems) or a rotating arm (circular systems) which can be usually operated at water depths of $10-20 \mathrm{~cm}$ for culture agitation, mixing and preventing the material from settling on the bottom (Richmond, 2003a; Chisti, 2007).

Most closed photobioreactors are designed as tubular reactors, plate reactors, or bubble column reactors (Pulz, 2001). Bioreactors when comparing batch or continuous systems, only continuous systems are realistically feasible for microalgal biomass (Banerjee $e t$ al., 2002). Ugwu et al., (2008) reported that the tubular photobioreactors are constructed with transparent glass or plastic, is one of the popular outdoor systems for mass algae cultivations.
Peer et al., (2008) reported that the closed photobioreactors were recommended for scaling up of autotrophic microalgae since this kind of bioreactor could save water, energy and chemicals compared to some other open cultivation systems. Commercial scale cultivation of microalgal biomass in photobioreactors is more successful.

Photobioreactors are the closed culture system and preferred over open ponds as they can be established and maintained either indoor or outdoor. But, the outdoor establishment is more successful because they can utilize free sunlight. Basically, these bioreactors allow for the cultivation of single microalgal species for prolonged duration under controlled conditions. Number of species such as Cyclotella cryptica, Monoraphidium minutum and Tetraselmis suecica has been successfully grown in closed photobioreactors for various purposes (Carvalho et al., 2006; Huntley and Redalje, 2007).

\section{Materials and Methods}

\section{Laboratory level open raceway pond setup}

The preliminary trials were conducted with laboratory set up raceway pond fabricated for the growth of microalgae of 190 L capacity made up of acrylic sheet. It is a transparent plastic material of $5 \mathrm{~mm}$ thickness. The laboratory setup was fabricated with the length $1.22 \mathrm{~m}$, width $0.41 \mathrm{~m}$ and height $0.3 \mathrm{~m}$. The pond was assembled over a steel structure to the height of $0.62 \mathrm{~m}$ from the ground level (Fig. 1). The lighting system objective is to simulate the sunlight in outdoor cultures. The lighting system was designed for cultures over the pond setup on the steel structure and maintained with $1.2 \pm 0.2$ klux light intensity under 16:8 light dark cycle (Dayananda et al., 2005). The ponds require a constant stirring for mixing and recirculation of the culture because it is necessary to avoid concentration 
gradients settling algae at the bottom of the pond and keeping in suspension. The stirring is produced by paddle wheel. The prime mower used for operating paddle wheel is electric motor. The speed is controlled from 10 to $40 \mathrm{rpm}$. The movement is transmitted from the motor to axle by a drive chain.

\section{Closed photobioreactor}

\section{Tubular photobioreactor (TPBR)}

Tubular photobioreactor (Fig. 2a) made up of acrylic tubes transparent type inner diameter of the tube $4 \mathrm{~cm}$, length of tube $1 \mathrm{~m}$ and thickness of tube $3 \mathrm{~mm}$, capable of holding 40 $\mathrm{L}$ of medium. The tubes were connected using rubber hose. The stand was fabricated using hylum sheet and steel structures.

\section{Cylindrical photobioreactor (CPBR)}

Cylindrical Photobioreactor (Fig. 2b) made up of acrylic sheet of $5 \mathrm{~mm}$ thickness of diameter $0.30 \mathrm{~m}$, height of $0.6 \mathrm{~m}$ which is capable of holding $15 \mathrm{~L}$ of medium with removable acrylic lids fixed with acrylic screws and suitable packing material at the top and bottom. Provision for holding 2 tube lights with acrylic holdings inside are sealed at the sides. Tube lights are connected externally to the power source. Provisions were provided for inlet at the bottom and outlet at the top with peristaltic pump for circulation of medium.

\section{Airlift photobioreactor (APBR)}

Airlift photo bioreactor (Fig. 2c) made up of acrylic sheet of $5 \mathrm{~mm}$ thickness, $0.5 \mathrm{~m}$ length, height $0.85 \mathrm{~m}$ and breath of $0.20 \mathrm{~m}$ capable of holding of $50 \mathrm{~L}$ of algal culture with removable acrylic lids fixed with acrylic screws and suitable packing material at the top and bottom. Provision for holding 4 tube lights on the stand are screwed at the back of the reactor and are externally connected to the power source.

All three photobioreactors were provided with

Storage tank (25 L capacity) for medium circulation

Suitable stand arrangement for the reactor, $\mathrm{pH}$ meter, Temperature controller, lux meter with data logger has been provided to measure $\mathrm{pH}$, temperature and light intensity of the microalgal culture.

\section{Mass cultivation of microalgae in} photobioreactor

All three types of photobioreactor were cultivated with the algal strain grown in laboratory culture. This experiment was conducted for a period of 25 days in batch mode. Once in two days the $\mathrm{pH}$, dry weight of algal biomass, light intensity and optical density were analyzed and recorded. Microscopic analysis was carried out weekly once to check the purity of the culture.

\section{Mass cultivation in open raceway pond}

The seed culture is grown in the laboratory conditions and the inoculums level of $5 \mathrm{~L}$ was transferred to the open raceway pond. The algal culture was mixed by paddle wheel during day time to prevent settling and enhance dissolved $\mathrm{CO}_{2}$ concentration. This experiment was conducted for a period of 60 days in batch mode. At 3 days interval, $\mathrm{pH}$, dry weight of algal biomass and optical density were analyzed and recorded. Microscopic analysis was carried out weekly once to check the purity of the culture. The daily temperature, humidity and solar radiation were also recorded during the experiment. At the end of the study period, the algal biomass was harvested and subjected to further analysis. 


\section{Results and Discussion}

Photobioreactors have had more significance, because they allow a better control of the cultivation conditions than open systems. Therefore, closed photobioreactors have some advantage: higher biomass productivities are obtained and contamination troubles are controlled.

\section{Operation of laboratory raceway pond}

The designed laboratory setup was tested in $T$. wisconsinensis microalgal culture. It was cultivated in $60 \%$ wastewater $+40 \%$ medium. The pilot plant has no temperature control system; therefore, the culture temperature will be maintained to laboratory temperature. The reasons for the choice of this algal strain were good oil content and easy obtaining strain in our region, provided by the Department of microbiology, TNAU, Coimbatore. The test consisted in 25 days of culture, divided in two harvests in different conditions. The objective of these tests was to check the illumination and stirring systems. During the culture growth the $\mathrm{pH}$, temperature and the biomass concentration was monitored.

The calibration curve in Figure 3 shows a strong relationship between biomass concentration and optical density. Hence the efficiency can be directly calculated from the OD.

The calibration curve may change from time to time during the algal lifetime. In different growth phases, variation in algal biological activity may lead to changes in chlorophyll concentration inside the cells. Therefore, even though cell 0numbers may be relatively constant, there would be dissimilar OD results because the OD measurement was based on absorption of chlorophyll by visible light.

Fig.1 Isometric view of lab scale raceway pond

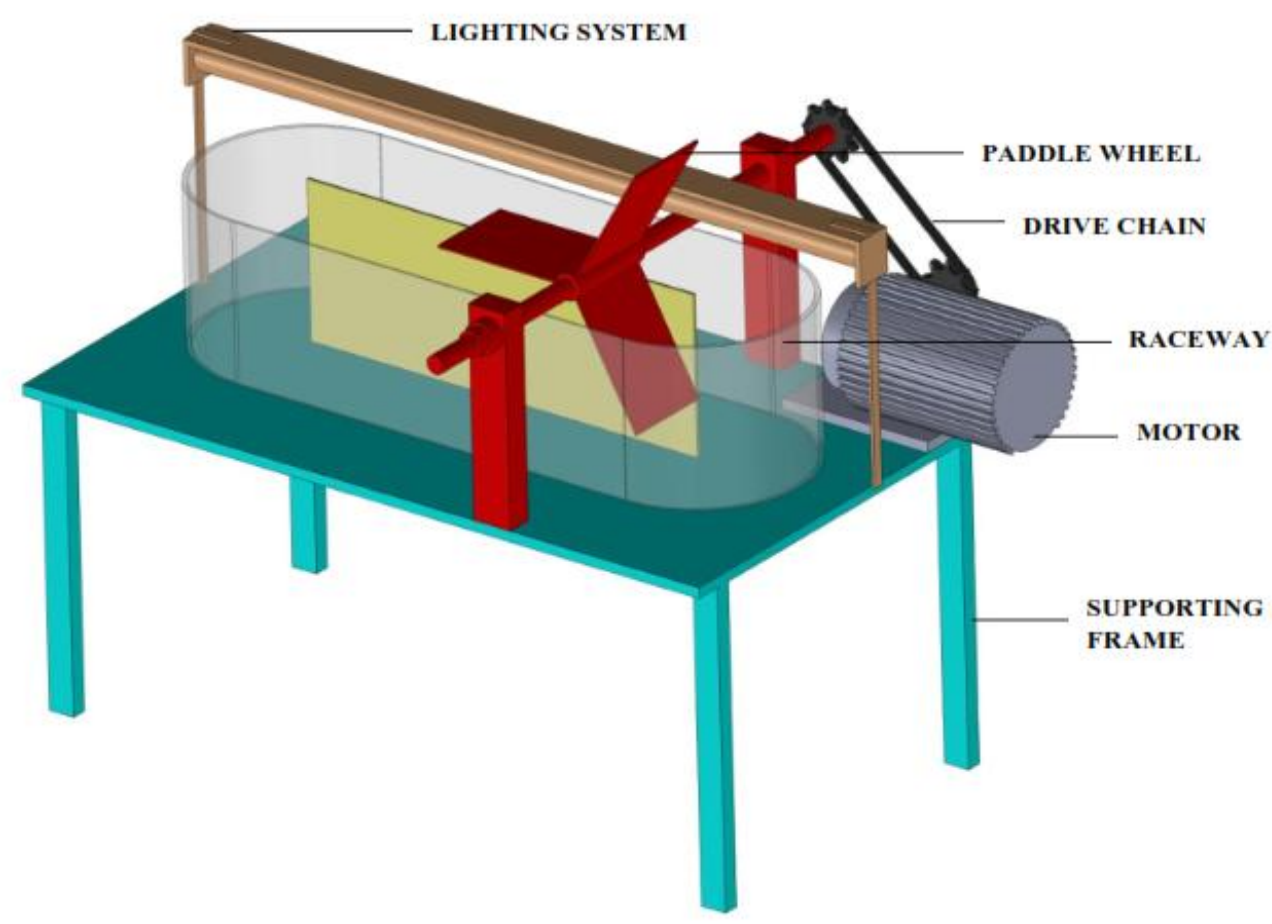




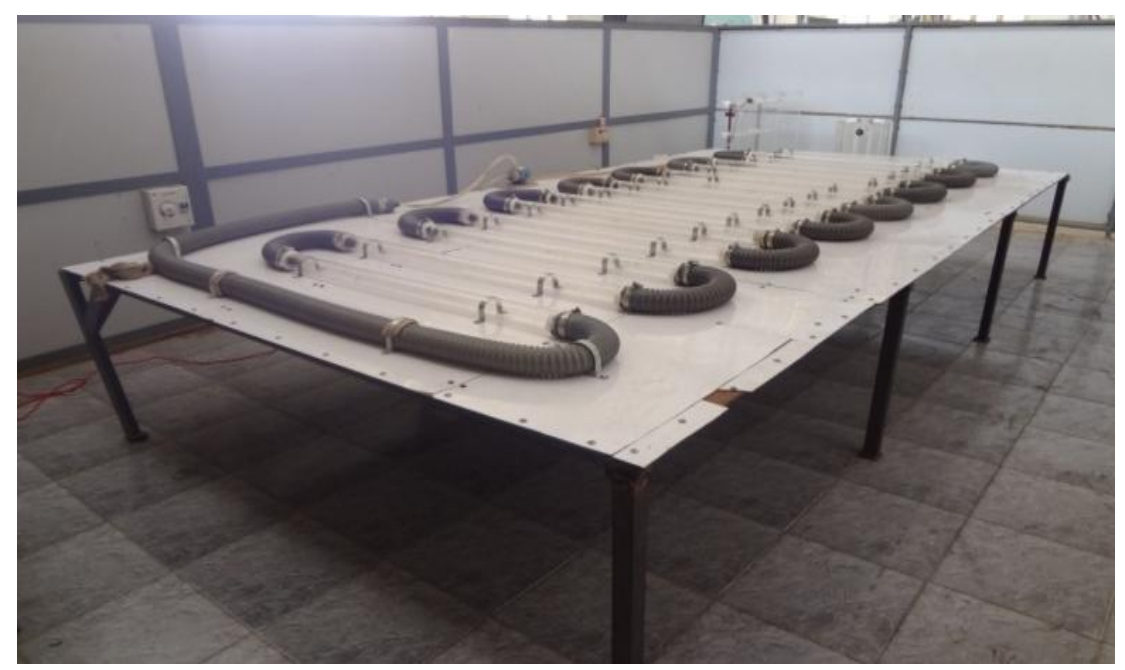

Fig.2a Tubular Photobioreactor

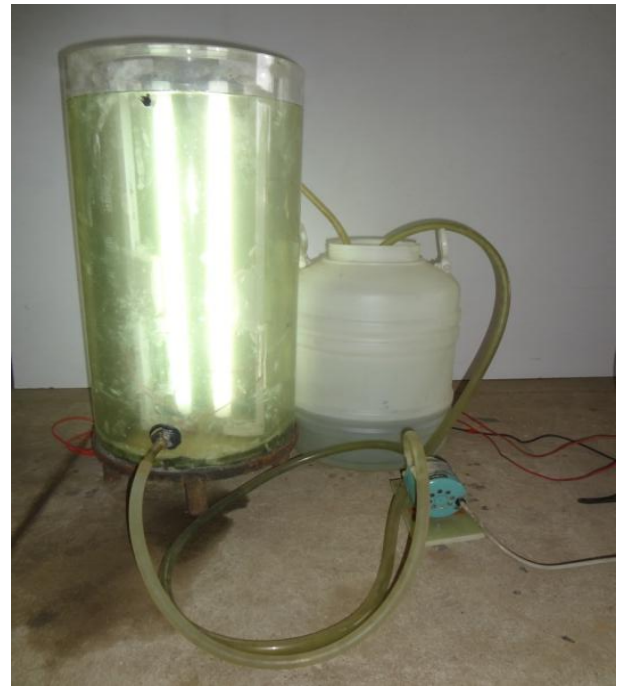

Fig.2b Cylindrical Photobioreactor

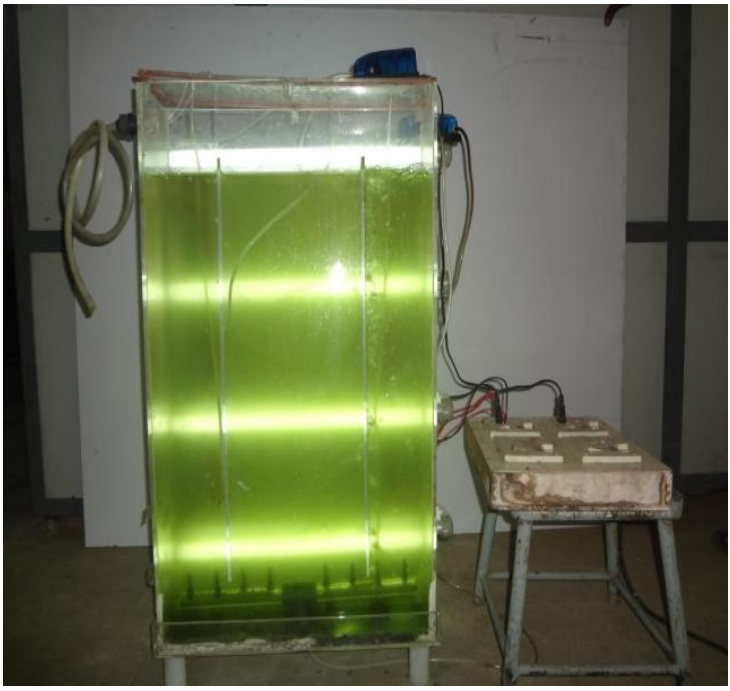

Fig.2c Air lift Photobioreactor

Fig.3 Effect of biomass concentration on growth of T. wisconsinensis in $60 \%$ wastewater $+40 \%$ medium in laboratory raceway pond

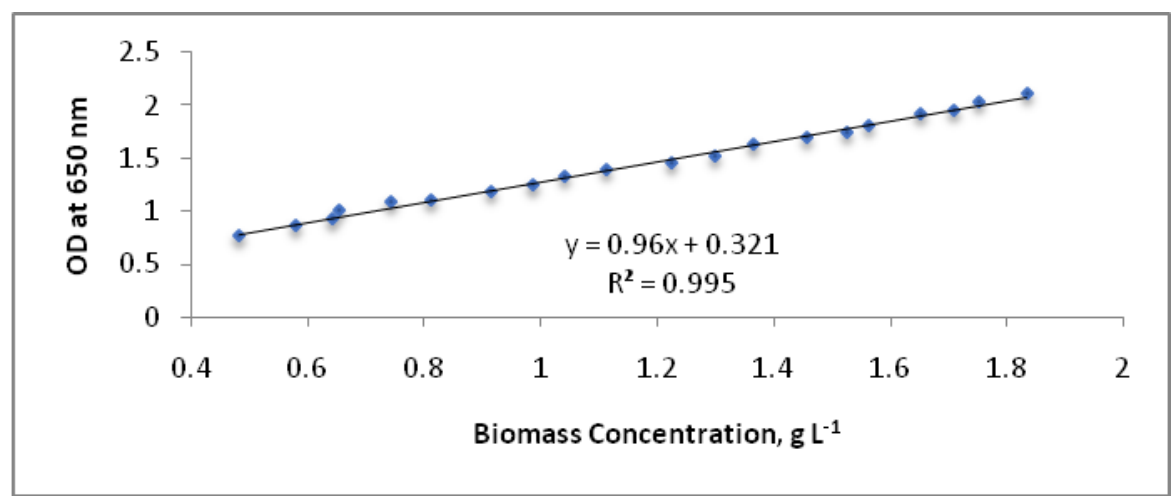


Fig.4 Temperature, $\mathrm{pH}$ dynamics and growth of $T$. wisconsinensis in $60 \%$ wastewater $+40 \%$ medium in laboratory raceway pond

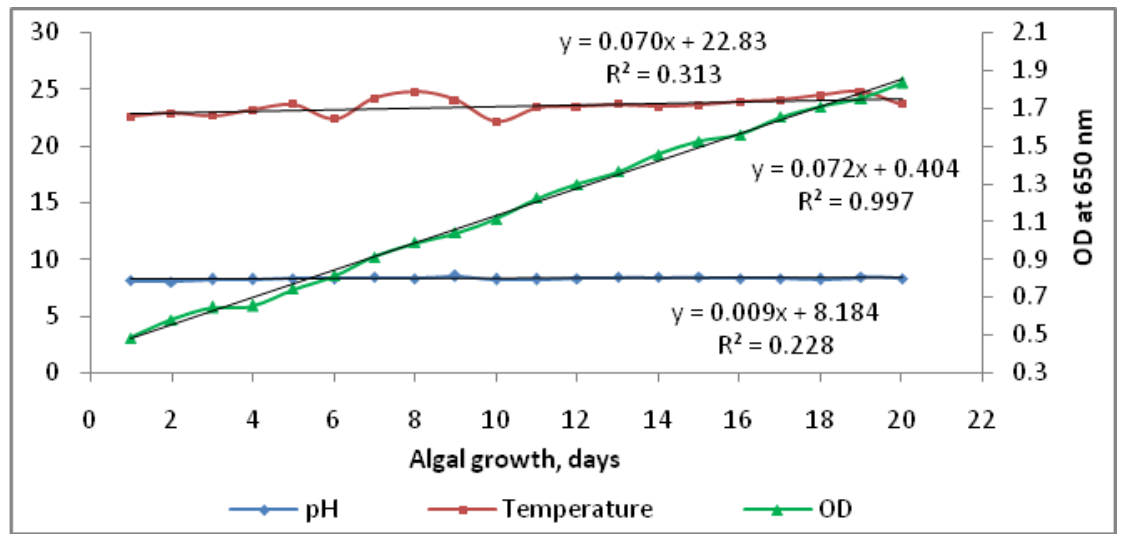

Fig.5 Comparison of Growth dynamics of $T$. wisconsinensis in photobioreactors

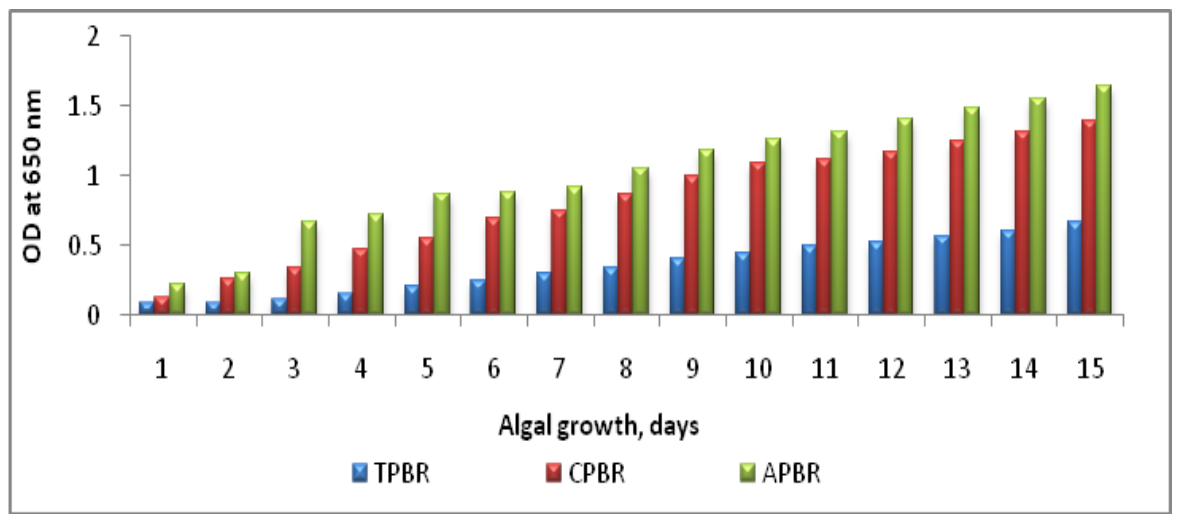

Effect of pH, temperature and biomass concentration

\section{Raceway pond}

The temperature and $\mathrm{pH}$ dynamics of $T$. wisconsinensis in $60 \%$ wastewater $+40 \%$ medium in lab scale open raceway pond is presented in Figure 4. The temperature was maintained to the laboratory condition (room temperature -22 to $25{ }^{\circ} \mathrm{C}$ ). The $\mathrm{pH}$ maintained at 8 to 8.5 almost throughout the study period which implies that uniculture of T. wisconsinensis was maintained in the raceway pond without contaminations. This was further confirmed by periodical observation by light microscopy.

\section{Closed photobioreactors}

The designed laboratory setup photobioreactors was tested in $T$. wisconsinensis microalgal culture. It was cultivated in $\mathrm{BG}-11$ medium. Algal cultures in open ponds have less productivity and enormous unhealthy batches. In recent years, closed system (photobioreactor) is considered as a way to mitigate all threats encountered in open ponds.

\section{Tubular photobioreactor (TPBR)}

It has a main tank connected to spiral tubes set in series. The main tank served as a feeding point of medium to the PVC tubes with a maximum capacity of 25 litres. Culture 
medium was pumped into the tubings at set at fixed flow rate. The selected algal strain was cultured in the TPBR to assess its functionality using fresh medium with no modification. Culture concentration and $\mathrm{pH}$ were measured over period of 15 days. A sample was taken every two day to measure the culture turbidity using a spectrophotometer (Agilent technologies, Cary 60, UV-Vis) at $650 \mathrm{~nm}$ and cells count using a microscope. The $\mathrm{pH}$ of culture was measured as well using $\mathrm{pH}$ test strip.

\section{Cylindrical photobioreactor (CPBR)}

It has a main tank connected to cylindrical tank. The tank served as a feeding point of medium to the cylinder with a maximum capacity of 15 litres. Culture medium was pumped into the cylinder at set at flow rate of 1.5 litre per minute. Culture concentration and $\mathrm{pH}$ were measured over period of 15 days. Light was supplied through 2 fluorescent lamps (18 watts) at the middle of the cylinder, and light intensity was measured by "Digicon LX-50 lux meter" around the cylindrical column. A sample was taken every two day to measure the culture turbidity using a spectrophotometer at $650 \mathrm{~nm}$ and cells count using a microscope. The $\mathrm{pH}$ of culture was measured as well using $\mathrm{pH}$ test strip.

\section{Airlift photobioreactor (APBR)}

Airlift bioreactors achieve mixing and mass transfer by injecting air into the riser compartment which then allows the fluid circulation through the downcomer compartment using double way air pump. Culture concentration and $\mathrm{pH}$ were measured over period of 15 days. Light was supplied through 4 fluorescent lamps (18 watts) at the side along the width of the column, and light intensity was measured by "Digicon LX-50 lux meter" around the column. The temperature was controlled at the room temperature. A sample was taken every two day to measure the culture turbidity using a spectrophotometer at $650 \mathrm{~nm}$ and cells count using a microscope. The $\mathrm{pH}$ of culture was measured as well using $\mathrm{pH}$ test strip. Figure 5 shows the cell growth in the photobioreactors. The airlift photobioreactor provided better performance than cylindrical and tubular reactor.

\section{References}

Banerjee, A., Sharma, R.Y.C. and Banerjee, U.C. 2002. Botryococcus braunii: a renewable source of hydrocarbons and other chemicals. Crit. Rev. Biotechnol. 22: $245-279$.

Carvalho, A.P., Meireles, L.A. and Malcata, F.X. 2006. Microalgal reactors: A review of enclosed system designs and performances. Biotechnol.Prog.22: 1490 - 1506.

Chisti, Y. 2007. Biodiesel from microalgae. Biotechnol. Adv., 25: 294 - 306.

Chisti, Y. 2008. Biodiesel from microalgae beats bioethanol. Trends Biotechnol. 26:126 - 131 .

Dayananda C, Sarada R, Bhattacharya S, Ravishankar GA. 2005. Effect of media and culture conditions on growth and hydrocarbon production by Botryococcus braunii. Pro. Biochem., 40:3125-3131.

Demirbas, A. 2011. Biodiesel from oilgae, biofixation of carbon dioxide by microalgae: a solution to pollution problems. Appl. Energ. 88 (10): 35413547.

Huntley, M.E. Redalje, D.G. 2007. $\mathrm{CO}_{2}$ mitigation and renewable oil from photosynthetic microbes: a new appraisal. Mitigat. Adapt. Strat. Global Change. 12: 573 - 608.

Kumar, S.M., Ramesh, A. and Nagalingam, B. 2011. An experimental comparison of methods to use methanol and 
Jatropha oil in a compression ignition engine, Biomass and Bioenergy. 25: 309-318.

Patil, V., Reitan, K.I., Knudsen, G., Mortensen, L., Kallqvist, T., Olsen, E., Vogt, G. and Gislerod, H.R. 2005. Microalgae as source of polyunsaturated fatty acids for aquaculture. Curr. Topics Plant Biol. (6): 57 - 65.

Peer, M., Skye, R., Thomas, H., Evan, S., Ute, C., Jan, H., Clemens, P., Olaf, K. and Ben, H. 2008. Second generation biofuels: high-efficiency microalgae for biodiesel production. Bioenerg. Res. 1(1): $20-43$.

Pulz, O. 2001. Photobioreactors: production systems for phototrophic microorganisms. Appl. Microbiol. Biotechnol. (57): 287 - 293.

Richmond, A. 2003a. Handbook of microalgal cultural: Biotechnol. Appl. Phycol. Wiley-Blackwell, Oxford.

Terry, K.L. and Raymond, L.P. 1985. System design for the autotrophic production of microalgae. Enzyme Microb. Technol. 7: $474-487$.

Ugwu. C.U., Aoyagi, H. and Uchiyama, H. 2008. Photobioreactors for mass cultivation of algae. Biores. Tech., 99: $4021-4028$

\section{How to cite this article:}

Kiruthika, R. and Kamaraj, S. 2017. Comparative Evaluation of Laboratory based Mass Cultivation System of Microalgae for Biodiesel Production. Int.J.Curr.Microbiol.App.Sci. 6(12): 1302-1309. doi: https://doi.org/10.20546/ijcmas.2017.612.147. 